\title{
Cryoetch And Cryo-planing For Low Temperature HRSEM: SE-I Imaging Of Hydrated Multicellular, Microbial And Bioorganic Systems
}

\author{
R.P. Apkarian, ${ }^{*}$ S.A. Shamsi, ${ }^{1}$ S.A. Rizvi, ${ }^{1}$ G. Benian, ${ }^{2}$ A.L. Neal, ${ }^{3}$ J.V. Taylor ${ }^{*}$ S.N. Dublin ${ }^{*}$ \\ * Integrated Microscopy \& Microanalytical Facility, Emory University, Atlanta, GA 30322 \\ ${ }^{1}$ Department of Chemistry, Georgia State University, Atlanta, GA 30302 \\ ${ }^{2}$ Department of Pathology, Emory University School of Medicine, Atlanta, GA 30322 \\ ${ }^{3}$ Savannah River Ecology Laboratory, University of Georgia, Aiken, SC 29802
}

Low temperature (LT) preparation of organic species and biological specimens in small volumes $(<5 \mu 1)$ by plunging in liquefied ethane or high pressure freezing (HPF) ensures rapid cryoimmobilization for subsequent processing and imaging with cryo-HRSEM. Provided that specimen concentrations are high enough to act as its own cryoprotectant, hexagonal ice formation may be avoided and the sample is preserved in the low temperature state. Subsequent processing by cryogenic fracture, cryo-planing, and high vacuum sublimation (etching) relieve surfaces for structural analysis in the nanometer range. Successful LT processing is completed by application of a thin monoatomic chromium $(\mathrm{Cr})$ film that enriches the SE-I contrast for high resolution cryo-HRSEM recordings.

Leucine-sulfate surfactants were prepared above the critical micelle concentration (CMC) and a 1-2 $\mu 1$ droplet was placed into a gold planchet (Balzers, 012 0130T). Similar volumes of lightly pelleted Shewanella oneidensis MR-1 gram negative bacteria and C-elegans were loaded into planchets and inverted such that the droplet surface was first to contact the ethane $\left(-183.3^{\circ} \mathrm{C}\right)$. For bioorganic suspensions such as surfactants and cells cryoimmobilized in planchets, transfers were made directly onto the Gatan CT-3500 cryostage housed in the cryo-workstation. Specimens were gently scraped with a prechilled blade so as to roughen the surface without removing the most likely vitrified portion of the sample, dual stage shutters were closed and the CT-3500 was transferred into the Denton DV602 Chromium sputter coater. Planchets containing LT C-elegans were transferred onto the chuck of a RMC 7000-CRX cryoultramicrotome in which both specimen and knife were maintained at $-150^{\circ} \mathrm{C}$ and cryo-planed. Planchets were mounted into the CT-3500 cryostage docked within the 7000-CRX chamber and transferred under dry $\mathrm{N}_{2}$ gas into the DV-602 high vacuum chamber ( $10^{-7}$ torr). Using the CT-3500 temperature controller the specimen was ramped from $-180^{\circ} \mathrm{C}$ to $-105^{\circ} \mathrm{C}$ for the appropriate etching time determined by experimentation $[1,2]$. Specimens were returned to $-180^{\circ} \mathrm{C}$ and argon plasma was established at $5 \times 10^{-3}$ torr for sputtering a $2 \mathrm{~nm}$ fine grain $\mathrm{Cr}$ film. The CT-3500 was shuttled into the lens of a Topcon DS-130 FESEM and allowed to equilibrate at $-120^{\circ} \mathrm{C}$ for $30 \mathrm{~min}$ prior to recording at $25 \mathrm{kV} .4 \mathrm{k} \mathrm{x} 4 \mathrm{k}$ digital recordings were processed using Adobe Photoshop.

As predicted by the CMC value, leucine sulfate surfactants appeared rod or tube-like in cryo-etch (3 min) LT-HRSEM images (Fig. 1). Nanorods ranged from 83-105 $\mathrm{nm}$ in width depending on the amount of remnant loosely bound LT water. Cross sectional cryoplaning of C-elegans followed by a brief 2 min etch revealed identifiable subcuticular body muscle cells (BMC) containing myofibrils (Fig. 2). Wild type S-oneidensis possess numerous pili (not shown) and flagella (Fig. 3). Their surface features and extracellular secretions have implications for their bioremediating properties. These three examples ranging from a whole multicellular organism to prokaryotic bacteria and chemical systems were routinely performed in our facility. They serve to demonstrate quality cryogenic preparation and imaging by in-lens FESEM employing TEM-type cryostages. 


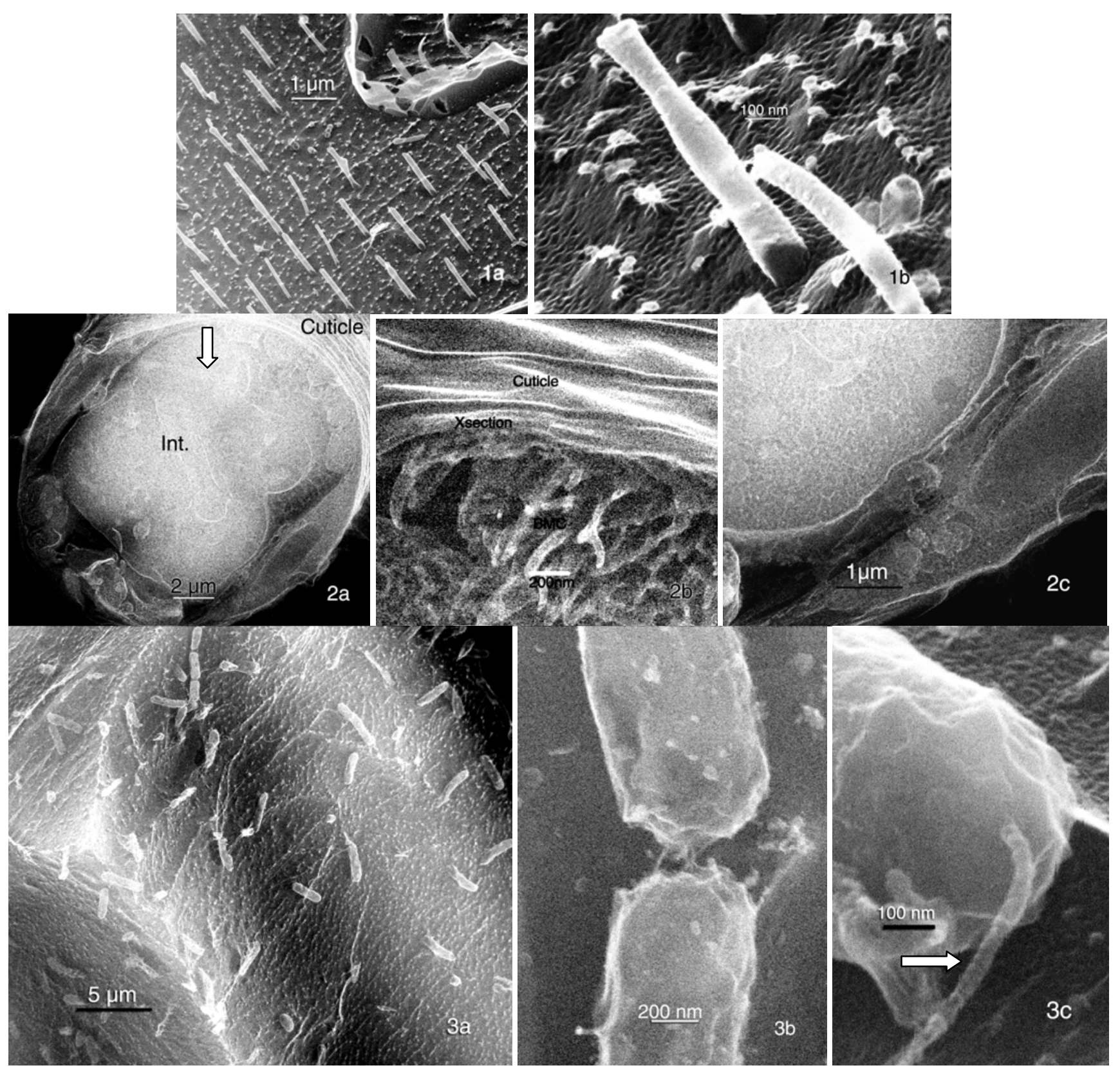

Fig. 1. Leucine-sulfate surfactant five times the CMC form rod-like structures (3 min etch).

Fig. 2. C-elegans was cryo-planed in cross-section (arrow) revealing (b) body muscle cell (BMC) myofilaments and (c) an epithelial cell.

Fig. 3. S- oneidensis were uncovered by a 15 min etch. Note flagella fine structure (arrow) in $3 \mathrm{c}$.

\section{References}

[1] R.P. Apkarian et al., Microsc. Microanal. 9:4 (2003) 286.

[2] E.R. Wright et al., Microsc. Microanal. 9:3 (2003) 171. 